This item was submitted to Loughborough's Research Repository by the author.

Items in Figshare are protected by copyright, with all rights reserved, unless otherwise indicated.

\title{
Transactive memory systems and Web 2.0 in knowledge sharing: A conceptual model based on activity theory and critical realism
}

PLEASE CITE THE PUBLISHED VERSION

http://dx.doi.org/10.1111/isj.12147

\section{PUBLISHER}

(c) Wiley

\section{VERSION}

AM (Accepted Manuscript)

\section{PUBLISHER STATEMENT}

This work is made available according to the conditions of the Creative Commons Attribution-NonCommercialNoDerivatives 4.0 International (CC BY-NC-ND 4.0) licence. Full details of this licence are available at: https://creativecommons.org/licenses/by-nc-nd/4.0/

\section{LICENCE}

CC BY-NC-ND 4.0

\section{REPOSITORY RECORD}

Simeonova, Boyka. 2017. "Transactive Memory Systems and Web 2.0 in Knowledge Sharing: A Conceptual Model Based on Activity Theory and Critical Realism". Loughborough University. https://hdl.handle.net/2134/25006. 
Transactive memory systems and Web 2.0 in knowledge sharing: a conceptual model based on activity theory and critical realism

\section{Boyka Simeonova}


Abstract. The aim of this paper is to advance understanding of interactive knowledge sharing $(K S)$ processes through exploring the role of transactive memory systems (TMS) and Web 2.0. In the context of the information systems (IS) literature, there is little focus on their particular role in KS. To address this gap, this paper develops a conceptual model based on activity theory and critical realism outlining the role of TMS and Web 2.0 as mediating tools. This paper further reveals that their use as tools depends on deeper underlying structures/factors embedded within the community, namely, informal networks and trust among people. The new conceptual model and theoretical propositions are then illustrated by a qualitative study undertaken in Bulgarian organisations. This illustrative case provides support for the model, where TMS and Web 2.0 are found to facilitate knowledge sharing. It further demonstrates that informal networks and trust among people support the use and the positive effects of these tools. The contribution of this paper is in the new analytical approach and conceptual model developed which advances our understanding of interactive KS by explaining the linkages between the various factors involved.

Keywords: activity theory, critical realism, transactive memory systems, Web 2.0, knowledge sharing

\section{Introduction}

Knowledge is recognised as an essential organisational asset leading to competitive advantage (Huang et al., 2011). The dominant view in the information systems (IS) literature is that knowledge is a commodity which can be transferred between people, in which technology is seen as playing a key part (Hislop, 2013; Galliers, 2006). IS research has been mainly focused on codifying knowledge and using information and communication technology (ICT) or knowledge management systems (KMS) to share knowledge, treating 'technology as a solution' (Allen et al., 2014; Davison et al., 2013; Kuswara \& Richards, 2011). However, it is increasingly recognised that traditional technologies are less able to support interactivity, which is much needed for sharing of knowledge embodied in practice (Newell \& Galliers 2006; Davison et al., 2013; Shollo $\&$ Galliers, 2016). Additionally, it is acknowledged that codification processes are costly and inefficient in contexts where informal, ad-hoc, and interactive knowledge sharing (KS) is more the cultural norm, such as China, Russia and Bulgaria (Michailova 
\& Husted, 2003; Hollinshead \& Michailova, 2001; Davison et al., 2013). From this perspective, knowledge sharing is viewed as a process where knowledge gets constructed and transformed through dialogue, interactions and socialising (Newell et al., 2009; Orlikowski, 2002).

More recent studies suggest that such knowledge sharing could be supported with the use of interactive Web 2.0 tools (Wagner \& Bolloju, 2005; Davison et al., 2013; Von Krogh, 2012), whose socially-driven and interactive features help overcome the limitations of the traditional ICT used in organisations (Kaiser et al., 2007; McAfee, 2006), and whose role is to facilitate action (Shollo \& Galliers, 2016). However, the effect of Web 2.0 technologies on knowledge processes, and the impact of their implementation in organisations, are under-explored in IS research (Huang et al., 2015; Von Krogh, 2012).

In relation to interactive and informal $\mathrm{KS}$, particular emphasis has also been given to transactive memory systems (TMS) (Jarvenpaa \& Majchrzak, 2008; Davison et al., 2013). Through TMS, people create mental maps of 'who knows what' (Choi et al., 2010; Jarvenpaa \& Majchrzak, 2008), which allows people to connect and to draw on other people's expertise (Akgun et al., 2006). However, there is little research on the relationship between TMS and knowledge sharing (Choi et al., 2010; Davison et al., 2013).

Together, these points provide the rationale for this study. The importance of interactive KS has been highlighted in the literature, especially in various cultural contexts, with Web 2.0 and TMS playing an enabling role, however, there is little understanding of what this role is. To address these gaps, this study posits two research questions: What is the role of TMS and Web 2.0 in interactive knowledge sharing processes? (RQ1), and, What are the underlying factors that affect the use of these tools? (RQ2). In order to answer these questions, activity theory (AT) is blended with critical realism $(\mathrm{CR})$ and a new conceptual model is proposed.

The model is illustrated by a qualitative study in Bulgarian organisations. This is a suitable setting to study the effect of Web 2.0 and TMS on interactive KS in that Bulgaria is in the process of becoming a Knowledge Economy (Bourdeau-Lepage \& 
Kolarova, 2008) with an increasing emphasis given by organisations to knowledgerelated processes. Little research exists so far in this context, however.

\section{Literature Review}

Regarding KS processes, the IS literature has mainly concentrated on codifying, storing and re-using knowledge, and sharing explicit knowledge via ICT or KMS (Davison et al., 2013; Kuswara \& Richards, 2011). Following this perspective, an IS theory widely adopted to explore KS is the sender-receiver model (SRM) (e.g. Ko et al., 2005; Joshi et al., 2007). SRM considers knowledge to be a transferable object, where knowledge sharing occurs between a sender and a receiver via a communication channel (Joshi et al., 2007). Within SRM, it is contended that KS depends on the amount of common knowledge between the sender and the receiver, and it is less about the meaning, action and construction of knowledge than about re-using it (Tortoriello et al., 2012).

Technology is often considered to be an efficient means of sharing knowledge as it crosses the boundaries of time and space (Singh, 2007). However, a number of issues are recognised where ICT solutions fall short in supporting KS processes. First, a large amount of knowledge within organisations is not codified and it is not easily transferable (Davison et al., 2013). Second, this view implies that people would naturally use the technology once it is made available, which may not necessarily be the case (Davenport \& Prusak, 1998). Third, technology is not able to substitute human interactions, meetings and dialogue (Prieto \& Easterby-Smith, 2006), and more recent studies assert that KMS cannot successfully enhance knowledge sharing without taking social and organisational aspects into account (Padova \& Scarso, 2012). This limitation is even more strongly recognised from the practice-based perspective where $\mathrm{KS}$ is seen to be driven by social interactions (Newell \& Galliers, 2006; Shollo \& Galliers, 2016).

Web 2.0 technologies are interactive tools extending social processes and relationships, connecting people, helping them create communities, and share ideas and thoughts with each other (Kuswara \& Richards, 2011; Von Krogh, 2012; Wakefield \& Wakefield, 2016). Web 2.0 technologies are platforms such as wikis, blogs, and social networking sites (Paroutis \& Al Saleh, 2009; McAfee, 2006). These technologies can help support interactive KS as such "new platforms focus not on capturing knowledge itself, but 
rather on the practices and output of knowledge workers" (McAfee, 2006, p. 23). A key objective of Web 2.0 is to allow for greater social networking behaviours and multivocality within the corporate context and enhance collaboration and interactivity between people (Schneckenberg, 2009; Von Krogh, 2012; Huang et al., 2013). However, it has been clearly established in the literature that merely deploying a new technology or tools, even interactive Web 2.0 platforms, does not necessarily lead to their use and to the sharing of knowledge (Davenport \& Prusak, 1998; Paroutis \& Al Saleh, 2009; Huang et al., 2013; Baptista et al., 2016). Furthermore, understanding the effects that such tools have on KS is in its early stages and more research is required in this area (Von Krogh, 2012; Huang et al., 2015).

Transactive memory systems are often viewed as an important factor supporting interactive and informal KS (Jarvenpaa \& Majchrzak, 2008; Davison et al., 2013), as they allow for the development of mental maps indicating 'who knows what', which helps to reach to the right people when needed (Choi et al., 2010). A central aspect of transactive memory systems is creating "the awareness of knowledge specialization among team members" (Kanawattanachai \& Yoo, 2007, p. 785), thus providing a pool of expertise to and of others. Hence, it is maintained that TMS can enhance knowledge contributions in organisations (Kanawattanachai \& Yoo, 2007; Alavi \& Tiwana, 2002). Furthermore, a fully-developed TMS can lead to effective knowledge sharing as well as to more informal KS (Oshri et al., 2008; Lewis et al., 2005; Choi et al., 2010; Davison et al., 2013). Although, it has been suggested that TMS has a positive effect on KS processes once it has been developed, little attention has been paid to the underlying factors stimulating TMS development, and more investigations are needed in this area (Ashleigh \& Prichard, 2012; Ren \& Argote, 2011).

\section{Theoretical background}

In order to answer the research questions posited in this study, the overarching framework of activity theory is adopted. The rationale behind the choice and a justification of the use of this theory is presented as follows.

\subsection{Activity theory}


Activity theory is a practice-based theory that assumes that knowledge is constantly evolving through collective activities (Blackler, 1995). Activity theory's dynamic view of knowledge resonates with the practice-based view of knowledge. Activity theory further suggests that people's activities are directed towards an object to achieve an outcome and are affected by the wider context in terms of community, division of labour, rules and tools mediating people's interactions (Engeström, 1987).

Activity theory was first introduced by Lev Vygotsky, who emphasised the interaction between the people and the world in terms of culture and society and stressed that this interaction is not direct but is mediated by tools (Vygotsky, 1978). He explains that the interaction between the subject and the object is always mediated by tools, which can be technical and/or psychological. This is regarded as the first generation/strand of activity theory; it focuses on the role of tools and does not account for the context and the environment where the activities take place.

The second strand of development of activity theory originated in Engeström's work (1987) which extended the theory to also consider the wider social context of the activity in terms of rules, community and division of labour. Within the activity system the subject performs an activity directed towards the object which results in an outcome (Engeström, 1987). The object is defined as the "thing that is being transformed or created" (Blackler \& Regan, 2006, p. 3). Objects can be physical/material, humans or ideal/intangible/abstract (Kaptelinin \& Nardi, 2006; Nicolini, 2013). The objects are moulded and transformed with the help of tools, which can be physical, symbolic, internal and external (Hasu \& Engeström, 2000). The rules comprise the norms and procedures that regulate the activities within the community (Engeström, 1987; Foot, 2001; Hasu \& Engeström, 2000). The community represents the environment where the activity takes place with others who, to some extent, share the same objective of work (Engeström, 1987; Foot, 2001; Hasu \& Engeström, 2000). The division of labour describes people's roles and responsibilities within the community. It accounts for both horizontal differentiation of tasks and roles as well as the vertical differentiation of power, status and access to resources and rewards (Engeström, 1987; Foot, 2001; Hasu \& Engeström, 2000; Nicolini et al., 2012). Therefore, this generation of activity theory accounts for the social and contextual factors affecting interactions and activities within 
the activity system. However, this line of enquiry has been critiqued due to its focus on a single activity system (Daniels \& Warmington, 2007).

The third strand in the development of activity theory represents two or more interacting activity systems, with a joint activity or practice, which share a common object (Engeström, 1999; Allen et al., 2013). It emphasises the multiple perspectives among interacting activity systems, as well as the use of diverse tools by different subjects in achieving a common object (Hasu \& Engeström, 2000; Daniels \& Warmington, 2007). It is further concerned with examining networks of activities, where different boundaries are crossed (Engeström, 2001). This third line of development of activity theory overcomes issues in the second generation by linking different activity systems, which has led to interesting applications in a number of areas such as healthcare (Hasu \& Engeström, 2000); learning (Daniels \& Warmington, 2007); crisis management (Allen et al., 2014).

This current study focuses on the use of TMS and Web 2.0 in knowledge sharing, where an activity system would help explore the role of these tools as well as the interplay with the other elements within the activity system. Therefore, the second generation of activity theory is adopted for the following reasons. It is a practice-based theory, allowing the investigation of interactive $\mathrm{KS}$; it suggests that activities are mediated by tools, both physical and abstract, thus helping to inform the role of Web 2.0 and TMS in KS; it accounts for context, i.e. cultural and social aspects of organisations, helping to identify other factors affecting the use of these tools and it recognises that contradictions are an intrinsic part of social interactions and activities, which allow the identification of any discrepancies and tensions in the use of Web 2.0 and TMS in KS. These different tenets of AT are now discussed and critically evaluated.

\section{Knowledge}

Activity theory recognises that knowledge is dependent on the context and it is enacted through actions and interactions (Blackler, 1995; Macpherson, 2005). Knowledge is described as mediated, situated, provisional, pragmatic and contested (Blackler, 1995; Allen et al., 2011). Additionally, the term 'best practice' is viewed as 'context-specific and practice-centred, and learning as an inherent aspect of participation in 
organisational activity", as opposed to equating knowledge transfer and learning with the rolling out of 'best practices', an assumption frequently held by the IS and knowledge transfer theories (Greig et al., 2012, p. 307). In this respect, it is argued that merely copying 'best practices' can force standardisation and reduce new knowledge creation (Galliers, 2006). Activity theory helps to overcome this issue in relation to 'best practices' as it is contended that knowledge is enacted in practice and evolving through collective activities (Blackler, 1995).

\section{Object-oriented activity}

Activity theory assumes that people's activities are directed at something in the world, i.e. towards an object and an outcome (Engeström, 1987). The object is described as real, constructed and emergent, and actors may have a partial understanding of the object and the reality (Engeström \& Blackler, 2005; Engeström \& Kerosuo, 2007). It is further stressed that it is the activities carried out in the specific context that, with the help of artefacts and others, affect and transform the subject and the object. Thus, assuming knowledge as the object of people's activities, activity theory can help unearth a rounded picture of the role of Web 2.0 and TMS as mediating tools in KS, and the deeper factors affecting the use of these tools, as well as the interaction of these factors within the activity system.

\section{Mediation}

According to AT, each activity is enacted through the dialectic relationship between the subject and the object, where "the object encompasses focus and purpose while the subject, a person or group engaged in the activity" (Hasan \& Pfaff, 2012, p. 427). An important tenet of activity theory is that all activities are seen as mediated by tools, which can be physical/material such as information systems, documents and telephones, or social/abstract, for example language, memory, or skills (Engeström, 2000; Allen et al., 2011). As such, the use of activity theory can help to overcome the overemphasis on 'technology as a solution' observed in the existing IS literature (Karanasios \& Allen, 2014; Kaptelinin \& Nardi, 2006; Crawford \& Hasan, 2006). This study suggests treating Web 2.0 technologies as mediating tools that support interactions between people in KS. Other studies have also adopted a similar view (e.g. Hasan \& Pfaff, 2012; Kuswara \& Richards, 2011), although not necessarily within the context of KS, which is what this study seeks to address. 
From the activity theory perspective, it is recognised that mediation can be external and internal (Vygotsky, 1978). It starts with an external mediation; for instance, when children learn to count, they make use of external tools, such as an abacus. During the course of practice and experience, counting becomes internalised, and children start doing it in their heads, which represents internal mediation. Mediating tools are seen as both the result of previous experiences as well as being constructed and re-constructed through actions and they guide the expansion, transformation and refinement of people's practices (Engeström \& Blackler, 2005; Miettinen \& Virkkunen, 2005). Within the context of this paper, TMS can serve as a good example of a mediating tool in knowledge sharing processes. Initially, TMS may be developed through external means such as face-to-face meetings, observations, collaborating on projects, teleconferencing, virtual teams, using KMS (Kanawattanachai \& Yoo, 2007; Oshri et al., 2008; Lewis, 2004; Alavi \& Tiwana, 2002). Through continuous interaction, TMS becomes internalised, whereby a person creates a mental map of 'who knows what' and 'who does what' (Choi et al., 2010). This mental map serves as a tool for the subsequent interaction between subjects. Therefore, following AT, this study suggests viewing TMS as a mediating tool, which helps support KS processes.

\section{Context}

Context is essential for organisations in general, and even more so in relation to knowledge sharing as people cannot be "understood in isolation from their contexts" (Blackler et al., 2000, p. 297). However, it is stressed that "the notion of context in information research remains broad and fluid", which is recognised as a major challenge (Allen et al., 2011, p. 783). Through examining the context in AT, i.e. community, division of labour, and rules, a greater understanding of the cultural, social, and historic influences can be achieved (Engeström, 1987; Allen et al., 2011). It is argued that all actions are culturally, historically and socially situated, and are contextspecific (Nicolini, 2013). Thus, activity theory helps to look deeper into the context which may enact or obstruct knowledge sharing activities and the use of tools to support them.

\section{Contradictions}


Activity theory assumes that activities are interwoven with internal contradictions (Engeström, 2000). In relation to activity theory, the term contradictions indicate "a misfit within elements, between them, between different activities, or between different developmental phases of a single activity" (Kuutti, 1996, p. 34). Manifestations of contradictions can be tensions, conflicts, discrepancies, problems, clashes, or dilemmas (Engeström \& Sannino, 2011; Kuutti, 1996; Hasu \& Engeström, 2000) within and between activity systems. This is another distinguishing feature of AT (Karanasios \& Allen, 2014), especially as, within other IS and KS theories, it is often assumed that knowledge processes are harmonious (Molina-Morales \& Martínez-Fernández, 2009). Importantly, resolving these contradictions leads to the development of new practices, change and innovation (Karanasios \& Allen, 2014; Engeström, 2008; Allen et al., 2011; Nicolini, 2013).

\section{Criticisms and Limitations of AT}

Activity theory has received great deal of attention in areas such as HCI (refer to Clemmensen et al., 2016 for an extensive review). It also has increasing resonance in IS research (Karanasios et al., 2015; Crawford \& Hasan, 2006; Miettinen \& Paavola, 2016). However, within the IS domain, activity theory has found limited application in relation to knowledge sharing (with notable exceptions Lin et al., 2008). Moreover, while activity theory is a practice-based theory viewing knowledge as enacted in practice, it appears that studies employing it treat knowledge as a tool within the activity system (e.g. Engeström, 2000; Hasan \& Gould, 2001; Lin et al., 2008). For example, Lin et al. (2008) investigated knowledge flow barriers within a healthcare unit describing that elements important for knowledge flow processes are: the knowledge sender (the subject), the knowledge receiver (the object), the context (the community) and the mechanisms (the tools), whereby knowledge and its characteristics are considered part of tools. In this stance, knowledge is viewed as a tool that can be exchanged between a sender and a receiver. Thus, it seems apparent that Lin et al. (2008) follow the classic sender-receiver model of knowledge flow for which the sender, the receiver and the knowledge characteristics are the main aspects of interest. Therefore, although some scholars have used AT to explore knowledge sharing, its application appears to be over-simplistic. 
It does appear that the view of knowledge commonly adopted by the AT-informed research follows the dominant IS view of knowledge as a commodity transferable between people via technology (Hislop, 2013; Galliers, 2006). Furthermore, some papers even consider information systems to be the community, within the activity system, where knowledge sharing and learning take place (e.g. Ryu et al., 2005). Such use of activity theory overemphasises the role of technology as a central aspect in KS, where knowledge is a tool transmitted via ICT. It is acknowledged that within activity theory "there is nothing in the material makeup of an artefact as such that would determine which one it is: object or tool" (Hasu \& Engeström, 2000, p. 64). For instance, an information system is a tool for the users, but an object for the designers (Hasu \& Engeström, 2000). A similar duality could be observed with regards to knowledge depending on the epistemological perspective adopted. From the practice perspective adopted in this study, knowledge is not a commodity passed between people, but rather "knowledge is seen to emerge as people interact recurrently in the context of established routines and procedures" (Newell \& Galliers, 2006, p. 442). In order to overcome this misunderstanding, the present paper treats knowledge as the object towards which the activities are directed and manifested as knowledge sharing processes, and technology, i.e. Web 2.0 is a tool mediating these activities.

Finally, while activity theory helps to identify the factors affecting knowledge sharing, it provides less clarity on the relationship between them. In order to highlight the links between the elements of the activity system, activity theory is blended with critical realism for the purposes of this study. We thus turn to a consideration of critical realism next.

\subsection{Critical Realism}

The aim of critical realist research is to understand what the components of the reality are, and how they interact to give rise to a particular set of events (Bhaskar, 1975). Critical realism posits that reality is stratified, and the occurrence of events depends on structures, mechanisms and contingent conditions, which illustrates that there is more to the world than simply a pattern of events (Mingers, 2004; Bhaskar, 1975; Sayer, 2000). 
Structures are "sets of internally related objects or practices" (Sayer, 1992, p. 92) that have causal efficacy, i.e. that have an effect, or make a difference, to behaviour (Fleetwood, 2004; Fleetwood, 2005). Mechanisms are defined as "inherent to physical and social structures, enabling or limiting what can happen within a given context" (Wynn \& Williams, 2012, p. 791). These mechanisms possess powers which could be enacted or not within a specific context (Fleetwood, 2004; Smith, 2006). For example, copper possesses the power to conduct electricity regardless of whether it is connected to an electrical circuit or not.

Events are defined as the "specific happening or action resulting from the enactment of one or more mechanisms" (Wynn \& Williams, 2012, p. 791). The occurrence of events is based on complex causality generated by the activated underlying mechanisms, structures and actions (Hesketh \& Fleetwood, 2006). Critical realism contributes to activity theory by helping to explore the deeper levels of structures, mechanisms and relationships that enhance or obstruct the events/outcome. The following table outlines AT's underlying assumptions and limitations, as well as the potential CR engagement and contribution, in order to develop a blended approach for investigating and understanding knowledge sharing processes.

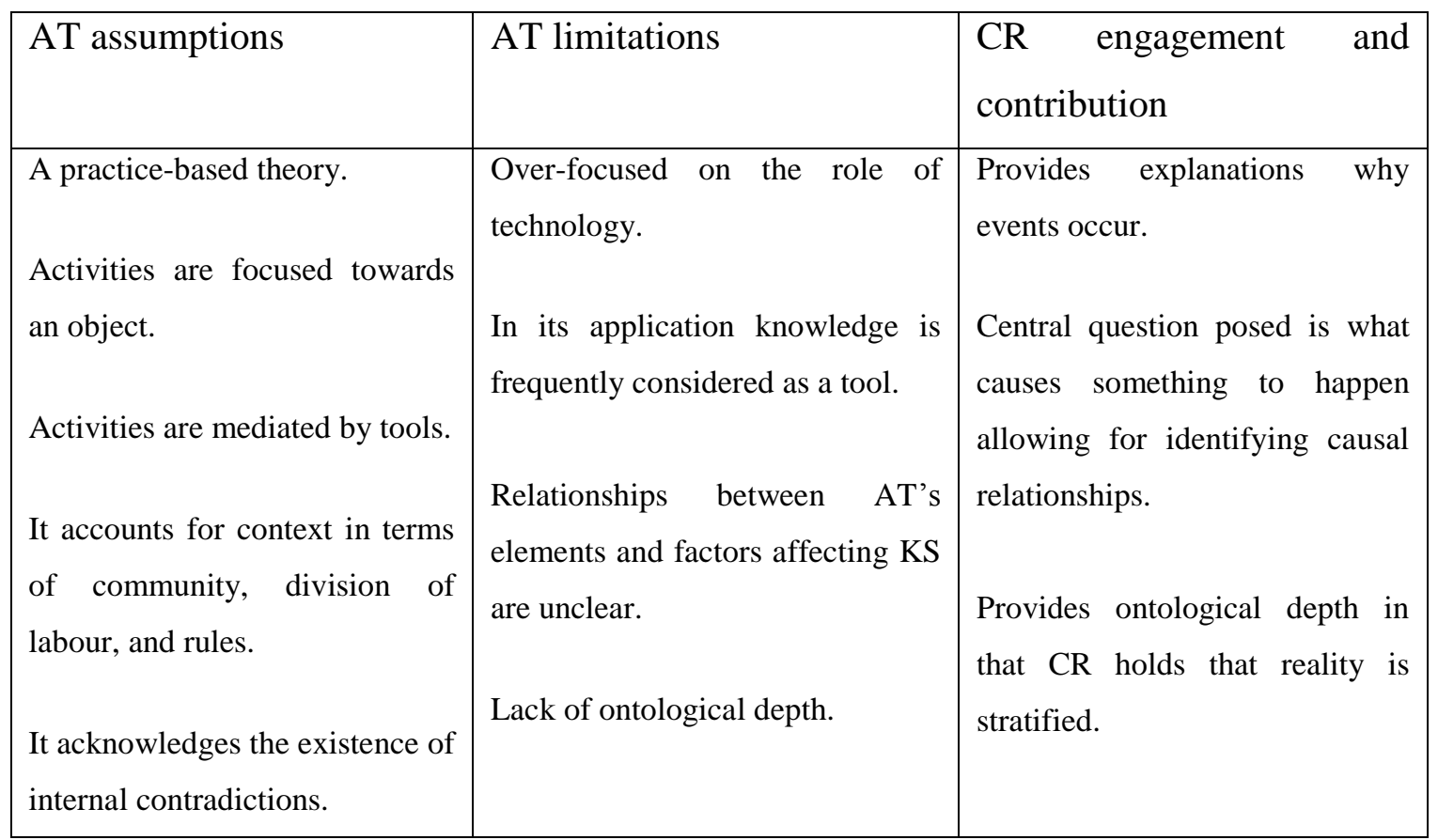


There is relatively little literature on how activity theory and critical realism can be complementary (Allen et al., 2013; Mingers, 2011; Mukute \& Lotz-Sisitka, 2012). The complementarity between activity theory and critical realism is explored in the following section. It also aims to address some of their limitations and advance both perspectives with an intent to develop a new analytical approach through the blending of AT and CR. The ways in which they can enhance each other and how they will be both used in the current study is presented in the following section.

\subsection{Blending activity theory and critical realism: a philosophical discussion}

The blending of AT and CR is based on their ontological and epistemological assumptions. It is stressed that the main focus of critical realism is "on ontology, not epistemology" (Sayer, 2000, p. 78). The strong ontological positioning of critical realism postulates that there is an independent and layered reality existing 'out there' separate from the individual.

The premise of critical realism is that observable events depend on the deeper structures and processes by which our knowledge is limited (Wynn \& Williams, 2012). As asserted by Bhaskar (1975) critical realism research aims to explore the components of this stratified reality as well as the underlying interactions that lead to observable events. The central question critical realism poses is: what caused something to happen? (Wynn \& Williams, 2012). Thus, critical realism emphasises the importance of understanding what provokes things to happen and why they are as they are (Easton, 2010).

Conversely, activity theory is presented more as an epistemological theory focusing on the collective activity towards a common object (Mukute \& Lotz-Sisitka, 2012). Ontologically, the activity theory principle of object-orientedness assumes that "human beings live in a reality that is objective in a broad sense: the things that constitute this reality have not only the properties that are considered objective according to the natural sciences but socially and culturally defined properties as well" (Kaptelinin \& Nardi, 2006, p. 67). Thus, critical realism can contribute to activity theory ontologically as the stratified ontology provides the opportunity for researchers to investigate how the 
different elements of the activity system interact in order to enact or obstruct the outcome (Clark et al., 2007). Critical realism allows for ontological depth as it goes beyond the events and explores the underlying structures and mechanisms that enable or obstruct the occurrence of events.

While critical realism is described as "ontologically bold", it is also considered as “epistemologically cautious" (Wynn \& Williams, 2012, p. 789). The epistemological position of critical realism is that independent, layered reality cannot be broken down to individuals' understanding as people's interpretations of reality differ (Sayer, 2000). Wikgren (2005) explains that "knowledge is communicatively constructed, that our concepts and beliefs are historically generated and conditioned, and that the explanatory knowledge produced through realist analysis will always be open to challenge and subject to change on theoretical and empirical grounds" (p. 14). It is argued that knowledge is continuously reproduced, and that theories are constantly refined to explain phenomena (Sayer, 1992). As such activity theory can enhance critical realism epistemologically by placing emphasis on knowledge as mediated, situated, provisional, pragmatic and contested within the activity system (Blackler, 1995). Activity theory emphasises the importance of the cultural and historical aspects of context, thus helping to put research into perspective of the relevant context (Allen et al., 2013).

Based on the assessment of the ontological and epistemological assumptions of AT and $\mathrm{CR}$, these two perspectives have been deemed complimentary as AT can enhance the understanding of knowledge, and CR can help with unpacking the deeper structures of reality.

A diagram representing the blending of $\mathrm{AT}$ and $\mathrm{CR}$ to address the issues raised in this paper is presented in Figure 1. 


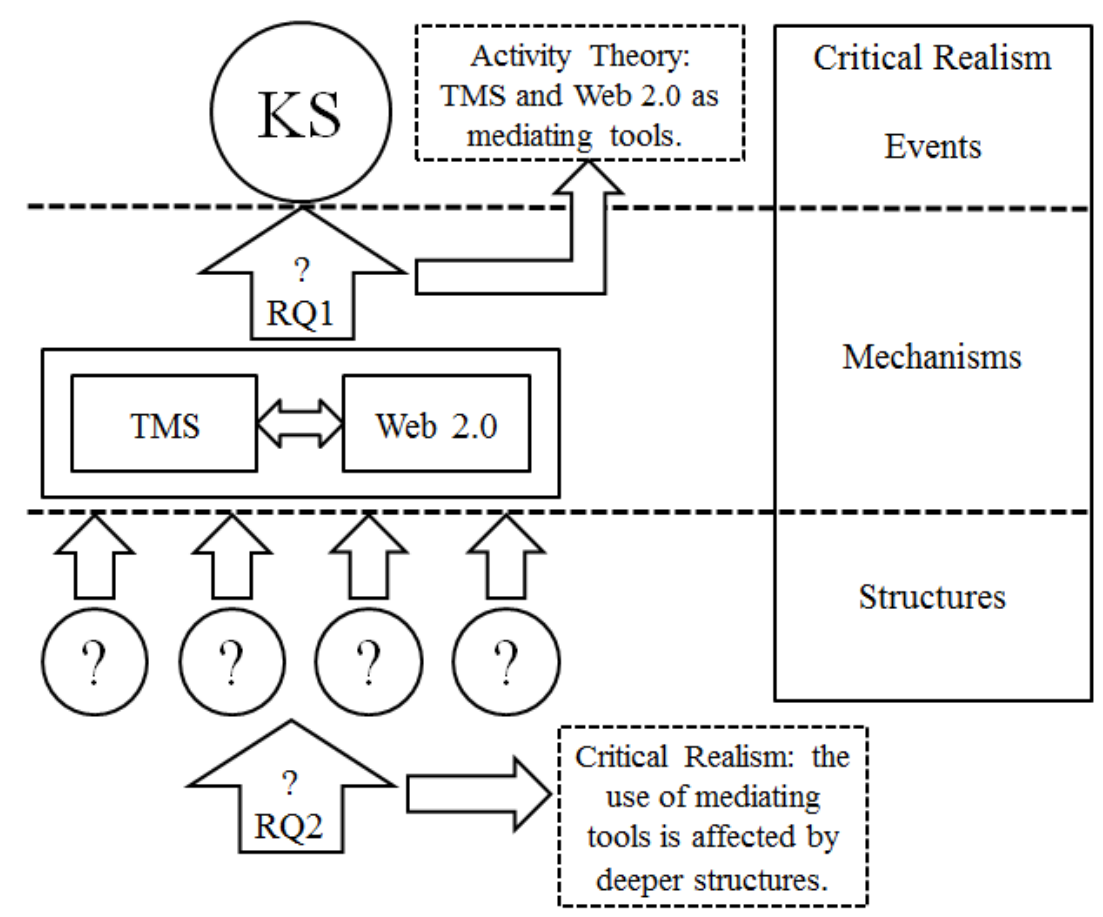

Figure 1: Blending of AT and CR: new analytical approach

The diagram illustrates how AT and CR can be used in conjunction to explore the role of Web 2.0 and TMS in KS, which constituted the first research question (RQ1). Following the activity theory framework, Web 2.0 and TMS are seen in this study as mediating tools facilitating interactive knowledge sharing. From a critical realist perspective, tools are treated as mechanisms which explain the occurrence of the event, i.e. knowledge sharing. At the same time, the effect of the mechanisms is underpinned by deeper structures - the bottom layer of the diagram; their nature constitutes the second research question (RQ2). To answer it, the underlying factors and relationships are identified in the next section where a conceptual model is developed and a number of theoretical propositions are put forward.

\section{Theoretical propositions}

A number of theoretical propositions are presented next based on the existing literature, illustrations from the Bulgarian context and the application of activity theory and critical realism. 


\subsection{The impact of Web 2.0 and TMS on KS}

Through TMS, a network is created where people are aware of each other's knowledge and can access it as and when required (Wegner, 1986; Choi et al., 2010). An important part of the knowledge sharing process is to locate the people with the expertise needed and for them to disclose the knowledge (Davison et al., 2013; Oshri et al., 2008; Choi et al., 2010). Thus, a developed TMS can be viewed as a tool enhancing knowledge processes as it helps to identify the knowledge and expertise required for the achievement of a task, which may be scattered throughout the whole organisation (Willem \& Scarbrough, 2006). This leads to the suggestion of the following proposition:

\section{P1: TMS facilitates knowledge sharing.}

Web 2.0 could also be seen as a valuable tool to promote knowledge sharing. Such technologies have been designed to enhance interactivity, socialising, expand social networks, allow for multitasking, and stimulate innovation and collaborations between people (McAfee, 2006; Schneckenberg, 2009; Davison et al., 2013; Von Krogh, 2012). A study by Kaiser et al. (2007) has identified that sharing knowledge via blogs provides an useful arena in which to express opinions, engage in discussions, overcome position and status differentials, and to increase cooperation and reciprocity in knowledge sharing, as well as improve information flow and knowledge sharing between departments (Benthaus et al., 2016). In another recent paper, Davison et al. (2013) suggest that in the Chinese context the use of interactive technologies supports informal knowledge sharing. Such technologies are seen as unintrusive, and their use supports KS through "making the right knowledge available to the right people at the right time" (Davison et al., 2013, p. 96). However, the results of Davison et al.'s (2013) study suggest that the effect is indirect, and is enacted through informal networks, i.e. guanxi, and transactive memory systems. In this paper, a direct relationship between Web 2.0 and KS is suggested, and the following proposition is put forward:

P2: Web 2.0 facilitates knowledge sharing. 


\subsection{Factors affecting the use of Web 2.0 and TMS development in Bulgarian organisations.}

Following AT, Web 2.0 and TMS are hereby considered as mediating tools supporting KS. However, as suggested by CR, the use of Web 2.0 and TMS development depends on deeper structures/factors. These are identified in the following sections.

The Bulgarian context has been selected in this study because it offers interesting challenges in relation to KS. Bulgaria is characterised by high levels of mistrust between people in organisations, suspicion, scepticism, high levels of bureaucracy and lack of business culture (Hollinshead \& Michailova, 2001; Bourdeau-Lepage \& Kolarova, 2008). Bulgarian culture has been described as having high power distance, high levels of uncertainty avoidance and cautious attitude towards outgroup members (Hofstede et al., 2010). A similar culture of mistrust is observed in Russia, where minimal trust, respect for hierarchy, and suspicion towards outgroup members have also been highlighted as important factors, which leads to minimal information disclosure and knowledge sharing (Michailova \& Husted, 2003). Therefore, establishing high levels of trust are required to support KS processes in such contexts. Additionally, for knowledge sharing to be successful, the importance of the interactive and informal nature of such processes in the Bulgarian context needs to be taken into account (Hollinshead \& Michailova, 2001). Parallels between the role of informal networks in such settings could be drawn with the Chinese concept of guanxi, which is found to nurture informal KS (Huang et al., 2011; Davison et al., 2013). In activity theory terms, trust and informal networks in this study are considered as embedded characteristics of the community where these interactions take place.

Trust is frequently defined as "the willingness of a party to be vulnerable to the actions of another party based on the expectation that the other will perform a particular action important to the trustor, irrespective of the ability to monitor or control that other party" (Mayer et al., 1995, p. 712). While the positive effect of trusting relationships on knowledge sharing has been well established in the literature (Hsu \& Chang, 2014; Willem \& Scarbrough, 2006), less is known about the effect such relationships have on TMS development. Ashleigh \& Prichard (2012) suggest that higher trust leads to greater TMS development as it promotes greater visibility and declaration of 
knowledge in the team, and in this way, a bigger picture of who knows what and who does what is revealed. Therefore, the following proposition is outlined:

\section{P3: Trust among people supports TMS development.}

It is also highlighted in the literature that face-to-face communication, observations and interactions are important factors enhancing TMS development (Lewis, 2004; Jarvenpaa \& Majchrzak, 2008). For example, it is suggested that guanxi, trusting relationships in China, strengthen TMS as in China the communication is predominantly informal, and is based on personal contact and networks (Davison et al., 2013). Similarly, Willem \& Scarbrough (2006) have found that informal networks are very useful in obtaining knowledge which is dispersed within an organisation. In the Bulgarian context people prefer personal contact and informal environments where people are at ease, which in turn makes knowledge sharing easier. Therefore, the following proposition is put forward:

\section{P4: Informal networks support TMS development.}

In relation to the use of Web 2.0, a recent study reveals that some of the barriers of using such technologies are related to different aspects of trust - i.e., trust in how people might use the information shared, in receiving reciprocal help from peers, and in accuracy of the information (Paroutis \& Al Saleh, 2009). Other studies identified that trust is a very important factor in virtual teams and communities as it is needed in order to disclose information via technology (Ridings et al., 2002). While the positive effect of the interpersonal trust, as defined earlier, on knowledge sharing is well documented, little is known about the effect of trust among people on the use of Web 2.0. It is thus proposed that greater trust among people would help them overcome the barrier of interacting via Web 2.0 technologies. Hence, the following proposition is suggested:

P5: Trust among people facilitates the use of Web 2.0.

Furthermore, investigating the use of Web 2.0, Paroutis \& Al Saleh (2009) identify that broadening one's network and access to discussions and other people's expertise are some of the main motivating factors which enhance the adoption of such technologies. 
Moreover, a study by Topi et al. (2006) reveals that the way people learn to use the corporate Enterprise Resource Planning (ERP) system is through the use of informal notes rather than through the formally available materials and training provided. Thus, if informal networks and interactions could enhance the use of the corporate systems, it can also be suggested that they could enhance the use of the Web 2.0 technologies available, as outlined in the following proposition:

P6: Informal networks help the use of Web 2.0.

Based on these theoretical propositions, a conceptual model is developed (see Figure 2) to illustrate the relationships between interactive KS, TMS, Web 2.0 and the underlying factors.

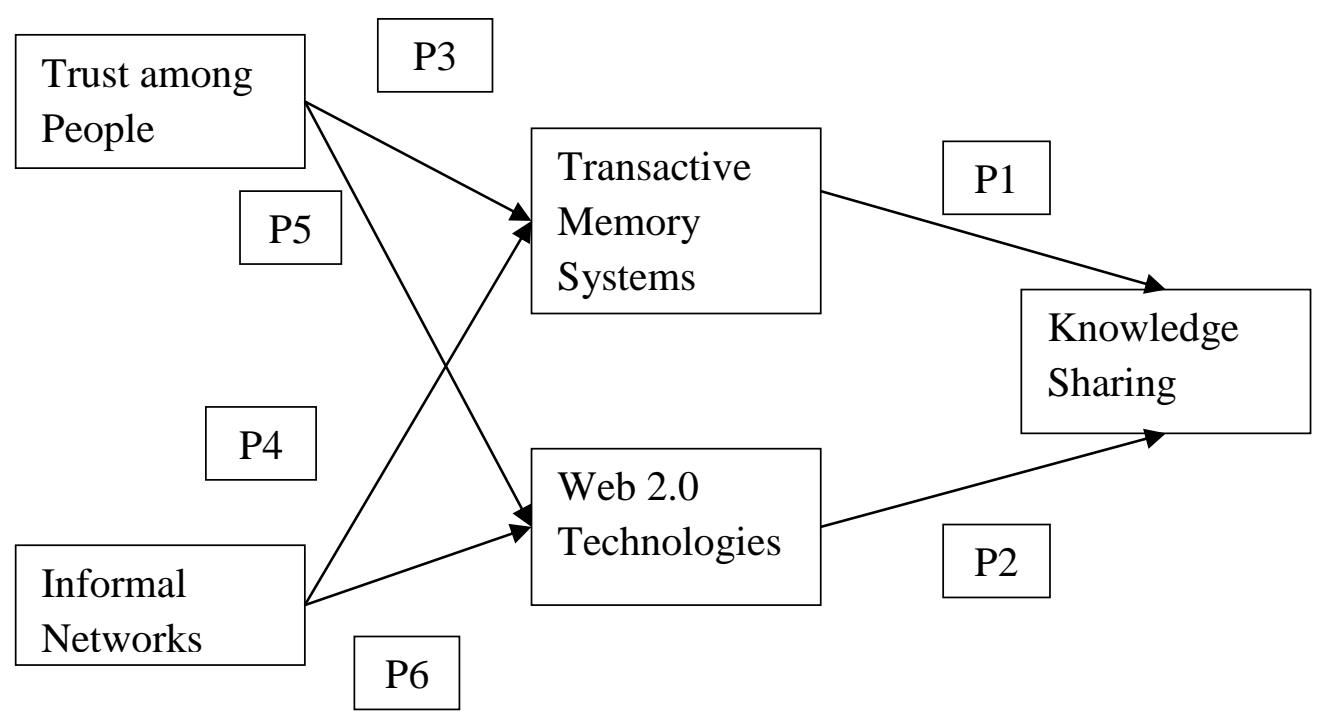

Figure 2: Conceptual model on knowledge sharing

\section{Research methodology}

In order to collect the data and to illustrate the propositions put forward in this study, semi-structured interviews were conducted. Semi-structured interviews are informal conversations guided by open questions allowing the interviewer to develop new ones during the course of the dialogue (Easterby-Smith et al., 2015). This technique gives the interviewee sufficient freedom to expand on particular points, and probe for examples of the matter under investigation, such as KS. 
Examples for the model developed were sought from knowledge-intensive firms, where knowledge sharing played an important role and was therefore more prominent. Thus, most examples came from IT/Software and management consulting sectors (ten firms), and also from media and publishing (two), manufacturing (two), a recycling company, a market analysis provider, a financial services agency, an energy supplier, a retail company, and a marketing agency. It is worth emphasising that the nature of the business was of much lesser importance than the knowledge intensity of the firm: none of the propositions the data illustrated were industry-specific.

For the qualitative interviews, a combination of purposeful and snowball sampling was used, in order to target and reach out to more participants (Bryman, 2012; Miles et al., 2014). Twenty semi-structured interviews lasting between 40 and 90 minutes were conducted. All interviews were audio recorded, transcribed, and translated. Eleven participants were top managers, five middle managers, and four operations managers. The size of the organisations varied, and two interviews were conducted in micro firms (<10 people), eight in small (10-49 people), eight in medium-sized firms (50-249 people) and two in large ones (>250 people).

The data were subjected to thematic analysis (Braun \& Clarke, 2006; Attride-Stirling, 2001). Attride-Stirling (2001) describes three stages of conducting thematic analysis: stage A: reduction or breakdown of text; stage B: exploration of text, and stage $\mathrm{C}$ : integration of exploration. As part of stage A, the interviews were transcribed, translated and were imported into the NVivo analytical software. Subsequently, the data was coded. The aim of coding is to combine, organise, reorganise the data in codes and themes, reflect on the data and make sense of its meaning (Miles et al., 2014). The codes represent statements and ideas from the interviews. These codes are subsequently grouped into themes (Easterby-Smith et al., 2015). At this stage the blended activity theory/critical realism framework is used to provide the underlying theoretical elements around which the themes are defined and the analysis performed. The themes are guided by the propositions: the role of TMS and Web 2.0 in interactive knowledge sharing as well as the effect of trust and informal networks on TMS development and the use of Web 2.0. As part of Stage B of the thematic analysis content corresponding to the propositions, outlined above, is detected. At this stage, AT and CR were used to 
build a rounded picture explaining the themes of interactive $\mathrm{KS}$ and the role of tools, Web 2.0 and TMS, to support it. In Stage C of the thematic analysis the findings of the semi-structured interviews are discussed in the light of the literature.

\section{Analysis and illustration of the theoretical propositions}

The analysis is presented in the following sections along the themes of interactive KS, TMS and Web 2.0.

\subsection{Interactive KS}

The concept of interactive knowledge sharing manifested itself in the fact that people tended to learn on the spot, and help each other to resolve problems in practice rather than through any formal procedures or training programmes. Participants explained that this was achieved through "explaining things to each other; you see how things are getting done as you are doing the job". The need to interact was seen as paramount as in the majority of companies people were not provided with any form of induction or formal training. Instead, they had to quickly adapt and learn on the job. The easiest way to adapt to a new environment was by getting help from people familiar with that environment. As one participant explained, "when a new member of staff joins, you show him how to do things so that he can do the work. We do not have one-month training course for all newcomers, but new people should be able to start working straight away". Moreover, it was stressed that "the best way to learn something is if someone shows and trains you". It was further emphasised that knowledge sharing took place "informally in any form - written or verbal". Participants further explained that KS was based on "informal conversation, chat, forum. The ones which are more formal are not the most popular as they are seen as an 'obligation' while otherwise people can choose the way to share with others according to their own preference".

\subsection{Transactive Memory Systems}

The importance of personal contact was strongly recognised in the development of transactive memory systems (TMS). The majority of participants stressed that "the first and the most important thing is to get to know everyone so that they know what you do 
and what you know as well as you know what they do". The use of TMS as a tool was evident from the interviews as most participants explained that "it is always the case where you need something urgently so whenever you need to know the right thing at the right time now, it is the best thing to ask someone who knows and who has already done this". In order to find the right person and the right expertise, people used job descriptions and organisational charts in larger organisations, while in smaller ones the process was a lot more ad-hoc as reported here. "If you do not know who knows what you need, then you go and ask verbally: 'Do you know about this, do you know about this, do you know about this?'. If you know someone that is likely to be aware of this problem or has experienced a similar problem, then possibly you can write him an email directly". Thus, a developed TMS served as a tool facilitating interactive knowledge sharing in Bulgarian organisations, illustrating Proposition 1.

Informal networks as a factor suggested to affect TMS development showed their significance in Bulgarian organisations as "people [who are] part of your informal network would be able to point you out to a colleague of yours that would give you the needed information". The importance of informal networks for TMS development and use was further explained by one participant who stressed that "you might not know everything, but you know where to find what you need". The findings show that TMS gets formed, used and updated through informal networks and social interactions, hence providing an illustration for Proposition 4.

The results further show that trust was recognised as a central factor for knowledge sharing. All participants put a strong emphasis on trust and some of them went as far as to say that "without trust nothing happens" and that "trust is crucial and if you lose it then the work becomes impossible". Building close and trusting relationships with people was "like putting money in a bank account and from the moment when you need it you are able to withdraw it". Therefore, high levels of trust among people facilitated seeking help from others. Additionally, when people trusted each other, they shared their knowledge more readily, stated their expertise and were more open to help others and to collaborate. This way, awareness of who knows what got developed, which people drew from when needed. The findings illustrate that, in line with Proposition 3 , trust among people facilitates TMS development. 


\subsection{Web 2.0 technologies}

Regarding the use of technology, the findings reveal that communication within Bulgarian organisations could be quite formalised as it mainly relied on emails, meetings, phone conversations, and considerably less on Web 2.0 platforms. The most utilised technological means were traditional emails. They appeared to be the management's preferred channel for communication as they leave a written trail. However, some participants held the view that "if we want to be in tune with the modern technologies, we cannot just say that we do not use them". So, it seemed that there was potential for embracing Web 2.0 technologies. However, only two companies out of twenty used them as a means of communication and knowledge sharing (KS). The Web 2.0 technologies used to share knowledge, in those companies that employed them, were mainly blogs and forums, and social networking sites were used a lot less.

The limited application of Web 2.0 within Bulgarian organisations was explained by the fact that their internal use was either banned or that employees' online presence was strictly monitored. The main reasons behind these restrictive measures appeared to be that management thought Web 2.0 to be distracting and it was considered that employees mainly used them to communicate with the outside world, which was seen as wasting their working time. As one participant explained, "now everyone uses [Skype] and social media such as Facebook, which really take a lot of people's time. So I took the measure to restrict access through the IP address and also to record how long each person spends on every website, so that I can control things". Another participant also pointed out that it was not right to use technologies such as Facebook and Skype as "in general they are quite distracting". This view was shared by the majority of the participants occupying upper levels within the organisations. However, some of them also recognised the value and advantages of using various channels in KS. As one participant explained, sometimes "a blog is more effective as it is accessible to everyone without having to organise formal meetings and so on". This illustrates the recognised potential of Web 2.0 to facilitate KS, however, positive attitudes towards the use of Web 2.0 were rarely expressed. Overall, the effect of Web 2.0 on interactive KS in Bulgarian organisations appeared to be unclear due to the ban. Hence, the findings do not provide a conclusive illustration for Proposition 2. 
Additionally, some participants suggested that technology was secondary in relation to the social dimension, and that the way people communicated and shared knowledge depended on the team spirit, the culture, and the levels of trust in the organisation. In other words, if there is low or no trust between team members, or between levels in the organisation, simply introducing Web 2.0 as a useful tool in supporting KS would not lead to more KS. On the contrary, low levels of trust can even lead to more negative attitudes towards Web 2.0, and sometimes to its complete ban. An illustration of this effect was provided by one participant who explained that "Initially [...] we were using Skype extensively with my employees to communicate and it was working out fine. But then the discipline got messed up and people were communicating more with the outside world than doing their jobs, so I banned it. The ban was not respected so the system administrator had to restrict the access through the IP address".

Furthermore, the findings show that greater trust among people would help to overcome the barrier of interacting via Web 2.0. This was illustrated by one participant who pointed out that "if you are constantly worried that someone will mess with you, or lie to you, or that he cannot do the job, then nothing happens". It is clear from these examples that the sufficient level of trust is a necessary condition for a successful implementation and use of Web 2.0 tools for KS. As such, these findings illustrate Proposition 5.

As suggested in this study, informal networks and interactions could enhance the use of the corporate systems and Web 2.0. The results illustrate this effect as "if you know someone that is likely to be aware of this problem or has experienced a similar problem, then possibly you can write them an email directly". However, the fact that the use of Web 2.0 had been banned within the majority of organisations presents a challenge in fully illustrating Proposition 6. The informality of Web 2.0 put in the context of low trust undermines the use of this tool, as management try to monitor and control people's interactions via technologies. However, should the use of such tools be allowed within Bulgarian organisations, the findings illustrate that established trust and informal networks would facilitate the use of Web 2.0. 


\section{Discussion}

In this paper, the role of Web 2.0 and TMS in interactive KS has been explored. Subsequently, deeper factors affecting the use of Web 2.0 and TMS development have been identified, namely trust among people and informal networks. To describe these relationships with greater precision, a number of theoretical propositions and a conceptual model have been developed (see Figure 2).

As made clear in the interviews, personal contact and forms of knowledge sharing based on dialogue and interactions are preferred in Bulgarian organisations. Such preferences have been shown to be present in similar cultural contexts, e.g. China (Davison et al., 2013). The findings show that such interactive knowledge sharing is facilitated by the TMS formed between people. In alignment with previous studies, it has also been demonstrated that TMS helps reach out to people who might be able to help with a particular task (Oshri et al., 2008; Choi et al., 2010). Furthermore, it has been shown that informal networks and greater trust among people support TMS development. These findings are in line with previous studies where guanxi in China is suggested to support TMS, which subsequently enhances informal KS (Davison et al., 2013). In this paper the role of informal networks as awareness mechanisms to help TMS development has been illustrated. The more people communicate in informal settings and within informal groups and networks, the more they become aware of who knows what and who does what within the organisation. An example of this is provided by Willem \& Scarbrough's work (2006) in which they show that a long-standing problem is resolved by locating the necessary expertise in another unit of the organisation through informal networking. Similarly, greater trust allows for greater declaration of one's expertise and greater willingness for cooperation (Ashleigh \& Prichard, 2012).

This paper further suggests that the use of Web 2.0 facilitates interactive knowledge sharing. The results illustrated that the views on the use of Web 2.0 within Bulgarian organisations are mixed. It has been revealed that only in a minority of organisations the use of Web 2.0 was encouraged and it facilitated knowledge sharing. However, in the majority of the organisations the use of Web 2.0 was banned. In this regard, some Bulgarian managers expressed concerns about interactive technologies being very 
distracting, hence their effect on knowledge sharing was somewhat challenged. In accordance with the concerns shown, previous research suggests that such interactive technologies are no more disruptive that the traditional phone calls, emails or unplanned meetings (Ou \& Davison, 2011).

While it could be argued that Web 2.0 possesses the potential to facilitate KS, such effect is not always enacted in the Bulgarian context where low trust prevails. This illustrates a major contradiction within Bulgarian organisations, where trust was shown to be an essential driving force. The results show that the use of Web 2.0 within organisations is frequently banned, as the management believes that people might misuse it or talk about non-work related matters. Such scepticism towards these technologies could be due to concerns that the open communication achieved through Web 2.0 use may pose a challenge to the rigid control systems (Allen et al., 2014; Huang et al., 2015). This is why traditional communication channels, such as emails, are preferred as they leave a track and can be easily monitored. In that respect, it has been pointed out in the literature that the use of informal technologies, such as Wikis, has the potential to threaten and undermine the strict management control (Hasan \& Pfaff, 2012; Pfaff \& Hasan, 2011) and promote multivocality, which may not align with the notion of a single organisational voice (Huang et al., 2013; Huang et al., 2015). However, it has been also found that for such technologies to be used for the benefit of the organisation, management needs to promote and endorse their use (Hasan \& Pfaff, 2012). The results in the latter paper show that the effect of informal and interactive technologies, in this case Wikis, is undermined by the hierarchy, the bureaucratic organisation, the competitive corporate culture, and the lack of management support (Hasan \& Pfaff, 2012). Contradictions related to leadership, tight control and management support have also been identified in other studies (Hasan \& Pfaff, 2012; Macpherson \& Jones, 2008; Macpherson, 2005). The current paper adds to this list the low levels of trust and the preference for strict control.

This finding could be outlined as another contradiction within Bulgarian organisations, as it is widely acknowledged that people prefer personal informal communication, and do not like formal KS and having to continuously put things in writing. Therefore, rather than installing tighter control measures, management should consider providing additional support to nurture this informal and interactive nature of sharing knowledge, 
where Web 2.0 could be a useful tool, capable of playing a crucial role in informal KS (Davison et al., 2013). These emerging contradictions are examples of secondary contradictions within the activity system. Secondary contradictions appear between the different elements of the activity system, e.g. rules, community, division of labour and tools (Engeström, 1987; Allen et al., 2013).

These findings suggest that power issues could also be put forward and understood as deep underlying factors that enact or hinder the use of tools for KS. Power is a multifaceted and ambiguous concept with no consensus within the literature on what it constitutes (Jasperson et al., 2002). Within the information systems, management and organisation studies literatures, the two most dominant perspectives on power are epistemic, power as a restraining force, and systemic, power as a productive force (Kärreman, 2010; Hislop, 2013). As a restraining force, power is regarded as a positional or personal resource which may restrict the behaviours of others, whilst, as a productive force, power is seen as an enabling resource, rather than as a restriction (Kärreman, 2010; Lawrence et al., 2012; Hislop, 2013). As the literature suggest power could be both a restrictive and an enabling force. Whilst this study exhibits examples of power as a restrictive force in the ban of using Web 2.0, it is suggested that a follow up study is needed to explore and unpack the miltfacetedness of the concept and its effect on KS and use of tools.

\section{Conclusions}

This paper offers a new approach to study KS and the role of IS as it sheds light on the deeper structures and factors affecting the use of tools. AT is used as a conceptual and analytical framework in combination with CR to develop a new conceptual model for the analysis and evaluation of KS, of the roles of tools and of the underlying factors affecting the use of these tools, with technology and systems seen as tools. Through the blending of AT and CR, a new analytical approach is developed which allows for the design of operationalised and testable propositions, which help investigate the role and effect of any tool/system to enable KS. In this respect, the new approach and model can be successfully applied in IS and KS research as it allows the investigation of any system and technology, but also the identification of deeper factors affecting the use of such tools in today's increasingly digitalised society. 
The development of this approach and blended model AT/CR provide a number of contributions. First, our understanding of AT is advanced by considering knowledge sharing as an outcome where knowledge is seen as the object towards which the activities are directed. This study helps to overcome the static view of knowledge as a tool and investigates knowledge as the object of people's activities. Second, this paper deepens the understanding of the role of Web 2.0 and TMS in KS via the use of AT, by providing insights into their role as mediating tools. This has been recognised as an area in need of more research as it is stressed that only recently studies have started to address "the issue of the role of technology in context as a mediating artefact in the search and acquisition of information" (Allen et al., 2011, p. 784). The third contribution is achieved through the blending of AT with CR, which enables identification of the deeper structures/factors which affect the use of these tools/mechanisms and the relationships between the different AT elements. This study reveals these deeper structures/factors to be informal networks and trust among people. Following the activity theory framework, trust among people and informal networks are treated as characteristics of the community which accounts for the context and the relationships between people. Thus, the contextual factors/structures within the activity system (trust among people and informal networks) support the use of the tools (Web 2.0 and TMS). This constitutes the fourth contribution to the use of AT, as a number of previous studies regard the community as a mediating artefact between the subject and the object (Hasan \& Pfaff, 2012; Hasan \& Gould, 2001; Lin et al., 2008), without accounting for the relationship between community and tools. Through the CR perspective, an ontological depth is provided, and it is revealed that the community factors are deeper structures affecting the use of the mediating tools/mechanisms in KS. An updated diagram of the blend of AT and CR, representing the newly developed approach, is presented in Figure 3. 


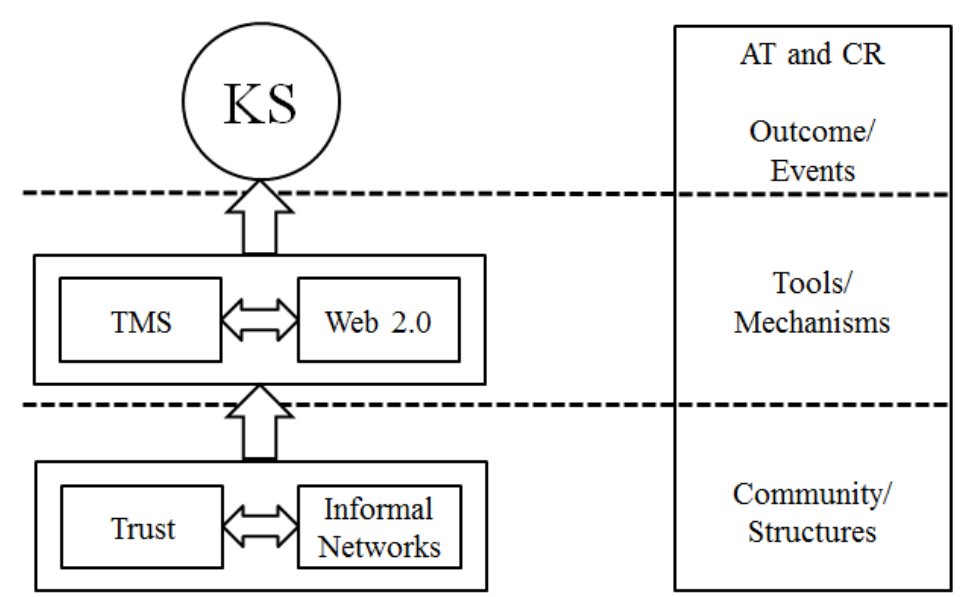

Figure 3: KS explained through blending AT and CR

AT and CR have been applied and extended to provide a new understanding of interactive knowledge sharing processes. This study enriches our view of the role of TMS and Web 2.0 as tools in knowledge sharing. It further reveals that the use of these tools depends on deeply embedded contextual structures (i.e., informal networks and trust among people). Through identifying these underlying factors, this paper contributes to calls in the literature regarding enablers and barriers in the use of Web 2.0 platforms (Von Krogh, 2012) and antecedents of TMS development (Ashleigh \& Prichard, 2012).

The newly developed conceptual model has been illustrated in a qualitative study in Bulgarian organisations. This illustration provides support for the facilitating effect of TMS on KS as well as the positive effects of trust and informal networks on TMS use and development. The findings are less conclusive on the role of Web 2.0 as a facilitating tool in $\mathrm{KS}$, where mixed results were elicited due to the general ban on the use of such technologies. Additionally, the findings demonstrate the potential of trust and informal networks to support the use of Web 2.0, but the effect of these was undermined by the aforementioned ban. This implied the existence of deeper underlying structures of power. Power issues need to be specifically studied to explore their effect on KS and on the use of tools. While this study provides support for the conceptual model proposed and it could be expected that it would be salient in other contexts as well, especially where interactive and informal KS takes place, the model needs to be further tested in a variety of settings. 


\section{References}

Akgun, A., Byrne, J., Keskin, H. \& Lynn, G. (2006) Transactive memory system in new product development teams. IEEE Transactions on Engineering Management, 53, 95-111.

Alavi, M., \& Tiwana, A. (2002) Knowledge integration in virtual teams: The potential role of KMS. Journal of the American Society for Information Science and Technology, 53, 1029-1037.

Allen, D. K., Brown, A., Karanasios, S. \& Norman, A. (2013) How should technologymediated organizational change be explained? A comparison of the contributions of critical realism and activity theory. MIS Quarterly, 37, 835855.

Allen, D. K., Karanasios, S. \& Norman, A. (2014) Information sharing and interoperability: the case of major incident management. European Journal of Information Systems, 23, 418-432.

Allen, D., Karanasios, S. \& Slavova, M. (2011) Working with activity theory: Context, technology, and information behavior. Journal of the American Society for Information Science and Technology, 62, 776-788.

Ashleigh, M. \& Prichard, J. (2012) An integrative model of the role of trust in transactive memory development. Group \& Organization Management, 37, 535.

Attride-Stirling, J. (2001) Thematic networks: an analytic tool for qualitative research. Qualitative Research, 1, 385-405.

Baptista, J., Wilson, A. D., Galliers, R. D. \& Bynghall, S. (2016) Social media and the emergence of reflexiveness as a new capability for open strategy. Long Range Planning (forthcoming).

Benthaus, J., Risius, M. \& Beck, R. (2016) Social media management strategies for organizational impression management and their effect on public perception. The Journal of Strategic Information Systems, 25, 127-139.

Bhaskar, R. (1975) A realist theory of science, Leeds: Leeds Books,.

Blackler, F. \& Regan, S. (2006) The conflicted object. AIM Workshop on Studying Practices Empirically, Aston University.

Blackler, F. (1995) Knowledge, knowledge work and organizations: An overview and interpretation. Organization Studies, 16, 1021-1046.

Blackler, F., Crump, N., \& McDonald, S. (2000) Organizing processes in complex activity networks. Organization, 7, 277-300.

Braun, V. \& Clarke, V. (2006) Using thematic analysis in psychology. Qualitative Research in Psychology, 3, 77-101.

Bryman, A. (2012) Social research methods: Oxford: Oxford University Press.

Choi, S., Lee, H. \& Yoo, Y. (2010) The impact of information technology and transactive memory systems on knowledge sharing, application, and seam performance: A field study. MIS Quarterly, 34, 855-870.

Clark, A. M., Macintyre, P. D. \& Cruickshank, J. (2007) A critical realist approach to understanding and evaluating heart health programmes. Health, 11, 513-539.

Clemmensen, T., Kaptelinin, V. \& Nardi, B. (2016) Making HCI theory work: an analysis of the use of activity theory in HCI research. Behaviour \& Information Technology, 35, 1-20.

Crawford, K., \& Hasan, H. (2006) Demonstrations of the activity theory framework for research in information systems. Australasian Journal of Information Systems, 13, 49-68. 
Daniels, H. \& Warmington, P. (2007) Analysing third generation activity systems: labour-power, subject position and personal transformation. Journal of Workplace Learning, 19, 377-391.

Davenport, T. \& Prusak, L. (1998) Working knowledge: Managing what your organization knows. Boston, MA: Harvard Business School Press,.

Davison, R.M., Ou, C.X.J. \& Martinsons, M.G. (2013) Information technology to support informal knowledge sharing. Information Systems Journal, 23, 89-109.

Easterby-Smith, M., Thorpe, R., \& Jackson, P. (2015) Management research, London; Thousand Oaks, CA : Sage Publications.

Easton, G. (2010) Critical realism in case study research. Industrial Marketing Management, 39, 118-128.

Engeström, Y. \& Kerosuo, H. (2007) From workplace learning to inter-organizational learning and back: The contribution of activity theory. Journal of Workplace Learning, 19, 336-342.

Engeström, Y. \& Sannino, A. (2011) Discursive manifestations of contradictions in organizational change efforts: A methodological framework. Journal of Organizational Change Management, 24, 368-387.

Engeström, Y. (1987) Learning by expanding: An activity-theoretical approach to developmental research. Helsinki: Orienta-Konsultit.

Engeström, Y. (1999) Innovative learning in work teams: analysing cycles of knowledge creation in practice, in Perspectives on Activity Theory, Engeström, Y., Miettinen, R., \& Punamäki, R. L. (eds.), Cambridge: Cambridge University Press, 377-406.

Engeström, Y. (2000) Activity theory as a framework for analyzing and redesigning work. Ergonomics, 43, 960-974.

Engeström, Y. (2008) Enriching activity theory without shortcuts. Interacting with Computers, 20, 256-259.

Engeström, Y., \& Blackler, F. (2005) On the life of the object. Organization, 12, 307330.

Fleetwood, S. (2004) Critical realist applications in organisation and management studies. In: Ackroyd, S. \& Fleetwood, S. (eds.) Realist Applications in Organisation and Management Studies. London: Routledge.

Fleetwood, S. (2005) Ontology in organization and management studies: A critical realist perspective. Organization, 12, 197-222.

Foot, K. (2001) Cultural-historical activity theory as practice theory: Illuminating the development of conflict-monitoring network. Communication Theory, 11, 5683.

Galliers, R. D. (2006) On confronting some of the common myths of Information Systems strategy discourse, in The Oxford Handbook of Information and Communication Technologies, Mansell, R., Avgerou, C., Quah, D. \& Silverstone, R. (eds.), Oxford: Oxford University Press, 225-243.

Greig, G., Entwistle, V. A., \& Beech, N. (2012) Addressing complex healthcare problems in diverse settings: Insights from activity theory. Social Science \& Medicine, 74, 305-312.

Hasan, H., \& Gould, E. (2001) Support for the sense-making activity of managers. Decision Support Systems, 31, 71-86.

Hasan, H., \& Pfaff, C. (2012) An activity-theory analysis of corporate wikis. Information Technology \& People, 25, 423-437. 
Hasu, M. \& Engeström, Y. (2000) Measurement in action: an activity-theoretical perspective on producer-user interaction. International Journal of HumanComputer Studies, 53, 61-89.

Hesketh, A. \& Fleetwood, S. (2006) Beyond measuring the human resources management-organizational performance link: Applying critical realist metatheory. Organization, 13, 677-699.

Hislop, D. (2013) Knowledge management in organizations: A critical introduction: Oxford: Oxford University Press.

Hofstede, G., Hofstede, G. J., \& Minkov, M. (2010) Cultures and organizations: software of the mind: intercultural cooperation and its importance for survival (Vol. 3rd). New York: McGraw-Hill.

Hollinshead, G., \& Michailova, S. (2001) Blockbusters or bridge-builders? The role of Western trainers in developing new entrepreneurialism in Eastern Europe. Management Learning, 32, 419-436.

Hsu, M. \& Chang, C. (2014) Examining interpersonal trust as a facilitator and uncertainty as an inhibitor of intra-organisational knowledge sharing. Information Systems Journal, 24, 119-142.

Huang, J., Baptista, J. \& Galliers, R. D. (2013) Reconceptualizing rhetorical practices in organizations: The impact of social media on internal communications. Information \& Management, 50, 112-124.

Huang, J., Baptista, J., \& Newell, S. (2015) Communicational ambidexterity as a new capability to manage social media communication within organizations. The Journal of Strategic Information Systems, 24, 49-64.

Huang, Q., Davison, R.M. \& Gu, J. (2011) The impact of trust, guanxi orientation and face on the intention of Chinese employees and managers to engage in peer-topeer tacit and explicit knowledge sharing. Information Systems Journal, 21, 557-577.

Jarvenpaa, S. \& Majchrzak, A. (2008) Knowledge collaboration among professionals protecting national security: Role of transactive memories in ego-centered knowledge networks. Organization Science, 19, 260-276.

Jasperson, J. S., Carte, T. A., Saunders, C. S., Butler, B. S., Croes, H. J. \& Zheng, W. (2002) Review: power and information technology research: a metatriangulation review. MIS Quarterly, 26, 397-459.

Joshi, K. D., Sarker, S., \& Sarker, S. (2007) Knowledge transfer within information systems development teams: Examining the role of knowledge source attributes. Decision Support Systems, 43, 322-335.

Kaiser, S., Müller-Seitz, G., Lopes, M. \& E Cunha, M. (2007) Weblog-technology as a trigger to elicit passion for knowledge. Organization, 14, 391-412.

Kanawattanachai, P., \& Yoo, Y. (2007) The impact of knowledge coordination on virtual team performance over time. MIS Quarterly, 31, 783-808.

Kaptelinin, V. \& Nardi, B. (2006) Acting with technology: Activity theory and interaction design, Cambridge, MA: MIT Press.

Karanasios, S., \& Allen, D. (2014) Mobile technology in mobile work: contradictions and congruencies in activity systems. European Journal of Information Systems, 23, 529-542.

Karanasios, S., Allen, D. \& Finnegan, P. (2015) Information Systems Journal Special Issue on: Activity Theory in Information Systems Research. Information Systems Journal, 25, 309-313.

Kärreman, D. (2010) The Power of Knowledge: Learning from 'Learning by Knowledge-Intensive Firm'. Journal of Management Studies, 47, 1405-1416. 
Ko, D, Kirsch, L., \& King, W. (2005) Antecedents of knowledge transfer from consultants to clients in enterprise system implementations. MIS Quarterly, 29, $59-85$.

Kuswara, A., \& Richards, D. (2011) Realising the Potential of Web 2.0 for Collaborative Learning Using Affordances. Journal of Universal Computer Science, 17, 311-331.

Kuutti, K. (1996) Context and consciousness: Activity theory and human-computer interaction, Cambridge, Mass.; London: MIT Press.

Lawrence, T. B., Malhotra, N. \& Morris, T. (2012). Episodic and systemic power in the transformation of professional service firms. Journal of Management Studies, 49, 102-143.

Lewis, K. (2004) Knowledge and performance in knowledge-worker teams: A longitudinal study of transactive memory systems. Management Science, 50, 1519-1533.

Lewis, K., Lange, D., \& Gillis, L. (2005) Transactive memory systems, learning, and learning transfer. Organization Science, 16, 581-598.

Macpherson, A. (2005) Learning how to grow: resolving the crisis of knowing. Technovation, 25, 1129-1140.

Macpherson, A., \& Jones, O. (2008) Object-mediated learning and strategic renewal in a mature organization. Management Learning, 39, 177-201.

Mayer, R., Davis, J. \& Schoorman, F. (1995) An integrative model of organizational trust. Academy of Management Review, 20, 709-734.

McAfee, A. (2006) Enterprise 2.0: The dawn of emergent collaboration. MIT Sloan Management Review, 47, 21-28.

Michailova, S., \& Husted, K. (2003) Knowledge-sharing hostility in Russian firms. California Management Review, 45, 59-77.

Miettinen, R. \& Paavola, S. (2016) Reconceptualizing object construction: the dynamics of Building Information Modelling in construction design. Information Systems Journal (forthcoming).

Miettinen, R. \& Virkkunen, J. (2005). Epistemic objects, artefacts and organizational change. Organization, 12, 437-456.

Miles, M. B., Huberman, A. M., \& Saldaña, J. (2014) Qualitative data analysis: A methods sourcebook, Thousand Oaks, Califorinia: SAGE Publications.

Mingers, J. (2004) Realizing information systems: Critical realism as an underpinning philosophy for information systems. Information and Organization, 14, 87-103.

Mingers, J. (2011) The contribution of systemic thought to critical realism. Journal of Critical Realism, 10, 303-330.

Molina-Morales, F., \& Martínez-Fernández, M. (2009) Too much love in the neighborhood can hurt: how an excess of intensity and trust in relationships may produce negative effects on firms. Strategic Management Journal, 30, 10131023.

Mukute, M. \& Lotz-Sisitka, H. (2012) Working with cultural-historical activity theory and critical realism to investigate and expand farmer learning in southern Africa. Mind, Culture, and Activity, 19, 342-367.

Newell, S., \& Galliers, R. D. (2006) Facilitating-or inhibiting-knowing in practice. European Journal of Information Systems, 15, 441-445.

Newell, S., Robertson, M., Scarbrough, H. \& Swan, J. (2009) Managing knowledge work and innovation, Basingstoke: Palgrave Macmillan.

Nicolini, D. (2013) Practice theory, work, and organization: An introduction, Oxford: Oxford University Press. 
Nicolini, D., Mengis, J. \& Swan, J. (2012) Understanding the role of objects in crossdisciplinary collaboration. Organization Science, 23, 612-629.

Orlikowski, W. (2002) Knowing in practice: Enacting a collective capability in distributed organizing. Organization Science, 13, 249-273.

Oshri, I., Van Fenema, P. \& Kotlarsky, J. (2008) Knowledge transfer in globally distributed teams: the role of transactive memory. Information Systems Journal, 18, 593-616.

Ou, C.X.J. \& Davison, R.M. (2011) Interactive or interruptive? Instant messaging at work. Decision Support Systems, 52, 61-72.

Padova, A. \& Scarso, E. (2012) Managing large amounts of knowledge objects: Cognitive and organisational problems. Knowledge Management Research \& Practice, 10, 287-295.

Paroutis, S. \& Al Saleh, A. (2009) Determinants of knowledge sharing using Web 2.0 technologies. Journal of Knowledge Management, 13, 52-63.

Pfaff, C., \& Hasan, H. (2011).Wiki-based knowledge management systems for more democratic organizations. Journal of Computer Information Systems, 52, 73-82.

Prieto, I., \& Easterby-Smith, M. (2006) Dynamic capabilities and the role of organizational knowledge: an exploration. European Journal of Information Systems, 15, 500-510.

Ren, Y. \& Argote, L. (2011) Transactive memory systems 1985-2010: An integrative framework of key dimensions, antecedents, and consequences. The Academy of Management Annals, 5, 189-229.

Ridings, C. M., Gefen, D. \& Arinze, B. (2002) Some antecedents and effects of trust in virtual communities. The Journal of Strategic Information Systems, 11, 271295.

Ryu, C., Kim, Y., Chaudhury, A., \& Rao, H. (2005) Knowledge acquisition via three learning processes in enterprise information portals: learning-by-investment, learning-by-doing, and learning-from-others. MIS Quarterly, 29, 245-278.

Sayer, A. (1992) Method in social science: A realist approach, London; New York: Routledge

Sayer, A. (2000) Realism and social science, London: Sage.

Schneckenberg, D. (2009) Web 2.0 and the empowerment of the knowledge worker. Journal of Knowledge Management, 13, 509-520.

Shollo, A. \& Galliers, R. D. (2016) Towards an understanding of the role of business intelligence systems in organisational knowing. Information Systems Journal, 26, 339-367.

Singh, S. (2007). What are we managing-knowledge or information? VINE, 37, 169179.

Smith, M. (2006) Overcoming theory-practice inconsistencies: Critical realism and information systems research. Information and Organization, 16, 191-211.

Topi, H., Lucas, W. \& Babaian, T. (2006) Using informal notes for sharing corporate technology know-how. European Journal of Information Systems, 15, 486-499.

Tortoriello, M., Reagans, R., \& McEvily, B. (2012). Bridging the knowledge gap: The influence of strong ties, network cohesion, and network range on the transfer of knowledge between organizational units. Organization Science, 23, 1024-1039.

Von Krogh, G. (2012) How does social software change knowledge management? Toward a strategic research agenda. The Journal of Strategic Information Systems, 21, 154-164.

Vygotsky, L. (1978) Mind in society: The development of higher psychological functions, Harvard, MA: Harvard University Press. 
Wagner, C. \& Bolloju, N. (2005) Supporting knowledge management in organizations with conversational technologies: Discussion forums, weblogs, and wikis. Journal of Database Management, 16, 1-8.

Wakefield, R. \& Wakefield, K. (2016) Social media network behavior: A study of user passion and affect. The Journal of Strategic Information Systems, 25, 140-156.

Wegner, D. M. (1986) Transactive memory: A contemporary analysis of the group mind, in Theories of group behavior, Mullen, B. \& Goethals, G. R. (eds.), New York: Springer-Verlag, 185-208.

Wikgren, M. (2005) Critical realism as a philosophy and social theory in information science? Journal of Documentation, 61, 11-22.

Willem, A. \& Scarbrough, H. (2006) Social capital and political bias in knowledge sharing: An exploratory study. Human Relations, 59, 1343-1370.

Wynn, D. \& Williams, C. K. (2012) Principles for conducting critical realist case study research in information systems. MIS Quarterly, 36, 787-810. 